\title{
Analysis of Pedestrian Violation Behavior Based on Herd Mentality Cao Yang ${ }^{1, a}$, Chen Shuyan ${ }^{1, b}$ and Xiao Zhongbin ${ }^{2, c}$ \\ ${ }^{1}$ College of southeast university, Department of Transportation, China \\ ${ }^{2}$ Yangzhou university, College of Science and Engineering, China \\ accaoyang@seu.edu.cn, ${ }^{\mathrm{b}}$ chenshuyan@seu.edu.cn, ${ }^{\mathrm{c}}$ zbxiao@yzu.edu.cn
}

\begin{abstract}
Keywords: traffic safety; herd mentality; binary logistic model; illegal crossing;expectation theory Abstract: For in-depth understanding of the effect mechanism of group crossing violation under the herd mentality, the pedestrian traffic data of typical signalized intersection in Yangzhou were collected by timely psychological inquiry. Then established a model of group conformity violation based on the herd mentality by binomial logistic model, and gave a quantitative analysis of the influence degree of herd mentality on the violation behavior. Finally combining expectancy theory and modeling results, the mechanism of violation behavior based on herd mentality was analyzed, and the corresponding countermeasures were put forward.
\end{abstract}

\section{Introduction}

Pedestrian traffic is an important part of city traffic. Pedestrians, as a "vulnerable group" in the traffic system, are more vulnerable in traffic accidents. According to the data of the ministry of public security of China, the number of casualties and direct economic losses in pedestrian traffic accidents in 2015 accounted for respectively $6.95 \%$ and $61.8 \%$ of non motor vehicle accidents ${ }^{[1]}$. The pedestrian traffic accident should not be underestimated. "Chinese style crossing the road" has become the main cause of pedestrian crossing accident. It shows that if there is a person crossing the street illegally during the red light, there will be a lot of people following him. This phenomenon involves many subjects, such as psychology and behavior. To alleviate this phenomenon, it is necessary to analyze the formation mechanism of illegal behavior from a multidisciplinary perspective.

\section{Literature Review}

Foreign scholars studied more deeply on characteristics of pedestrian behavior in street crossing. Chu (2002) designed questionnaire to understand the respondents' preference, and used nested logit model to study the behavior of pedestrians crossing the street ${ }^{[2]}$. The behavioral differences of pedestrians of different ages and genders in dangerous environment were studied by Holland ${ }^{[3,4]}$. In terms of influencing factors, Zaki analyzed group crossing behavior from video data ${ }^{[5]}$. Onelcin analyzed the factors affecting violation behavior such as vehicle position and time gap ${ }^{[6]}$. The influence of visual environment on pedestrian crossing decision is studied from the aspects of road facilities and pedestrian self expectation by Brémond ${ }^{[7]}$ and Marie ${ }^{[8]}$. In addition, based on the theory of planned behavior, Barton studied the attitude and perceived behavior control of pedestrians during distraction, which provided the basis for the development of measures ${ }^{[9]}$.

In China, scholars pay more attention to the phenomenon of illegal crossing based on herd mentality recently. Zhou analyzed the law of pedestrians' illegal crossing based on the network theory ${ }^{[10]}$. Li feng et al. built a model about the behavior recognition process of the subject from the perspective of psychological threshold ${ }^{[11]}$. Based on the theory of planned behavior, the correlation between different factors and the conformity of pedestrians is obtained by Zhou ${ }^{[12]}$. Mei used the theory of diffusion and complex networks to establish an analytical model of conformity psychology in violation crossing ${ }^{[13]}$. Li proposed a collective behavior threshold model, and obtained the critical value of the phase transition of collective action by simulation ${ }^{[14]}$. Based on evolutionary game theory, Wu studied the pedestrian crossing behavior ${ }^{[15]}$.

In summary, research content of foreign researches is more detailed, in-depth and mainly focuses on the study of human behavior characteristics. Previous studies in China have conducted a simple 
statistical analysis from a psychological point of view, and have attempted to analyze them with new models in recent years. But the above researches rarely use data which can directly reflect the psychology of violation, simply speculate by walking rules. This research aimed to address this knowledge gap. Using timely psychology inquiries to collect data, using binary logistic model to analyze various influencing factors, combining with expectation theory, we got the specific countermeasures on illegal crossing behavior based on herd mentality.

\section{Data}

We collected data through field surveys. The intersection of jiangyang west road and hanjiang mid road in Yangzhou was chosen as the survey site. Both the two roads are urban main road and the traffic function is strong. The nearby land is mainly for recreation and accommodation which can attract large traffic flow, and has great research value.

On the one hand, the pedestrian characteristics (age, gender, number, etc.), crossing behavior (walking status, is there a car, the number of people crossing illegally etc.) were observed; on the other hand, inquired the psychology of violation (violation of psychological, risk perception, etc.) and so on questions.

After screening to remove invalid data, we obtained 535 valid data, including 331 illegally crossing data. Variable description is shown in Table1.

Table 1. Variable description

\begin{tabular}{|c|c|c|c|c|}
\hline \multicolumn{3}{|c|}{ Variable name } & pattern & $\begin{array}{l}\text { Variable interpretation and } \\
\text { assignment }\end{array}$ \\
\hline \multicolumn{2}{|c|}{ Dependent variable } & Illegally crossing & Binary & yes $=1 ;$ no $=0$ \\
\hline \multirow{4}{*}{$\begin{array}{l}\text { Indepen- } \\
\text { dent } \\
\text { variable }\end{array}$} & $\begin{array}{l}\text { Personal } \\
\text { attributes }\end{array}$ & $\begin{array}{l}\text { Gender } \\
\text { The number of } \\
\text { people crossing } \\
\text { together }\end{array}$ & $\begin{array}{c}\text { Order multiple } \\
\text { classification } \\
\text { Binary } \\
\text { Continuous } \\
\text { variable }\end{array}$ & $\begin{array}{c}<16=1 ; 16-35=2 ; 35-60=3 ;> \\
60=4 ; \\
\text { male }=1 ; \text { female }=2\end{array}$ \\
\hline & \multirow{3}{*}{$\begin{array}{l}\text { Illegally } \\
\text { crossing } \\
\text { attributes }\end{array}$} & $\begin{array}{l}\text { Psychology of } \\
\text { violation }\end{array}$ & $\begin{array}{l}\text { Disordered } \\
\text { multiple } \\
\text { classification }\end{array}$ & $\begin{array}{l}\begin{aligned} \text { herd mentality }=1 ; \text { anxious }=2 ; \\
\text { fluke mind }=3 ; \text { unconscious mind } \\
=4 ;\end{aligned}\end{array}$ \\
\hline & & $\begin{array}{l}\text { Danger sense } \\
\text { Walking state }\end{array}$ & $\begin{array}{l}\text { Ordered multiple } \\
\text { classification } \\
\text { Disordered } \\
\text { multiple } \\
\text { classification }\end{array}$ & $\begin{array}{c}\text { level ranges between } 1 \text { and } 4 \\
\text { walk=1 ; walk after run=2 ; run } \\
\text { after walk=3; run=4 }\end{array}$ \\
\hline & & $\begin{array}{l}\text { Stop during the } \\
\text { walk }\end{array}$ & Binary & $\mathrm{Yes}=1 ; \mathrm{no}=0$ \\
\hline
\end{tabular}

\section{Methodology}

Timely Psychological Inquiry. This is an innovative method adopted in this study, which makes up for the deficiency in some literature that mental data cannot be obtained. The specific approach is: when observing the violation crossing, the observer proceeded to ask violator the questions set by the psychological professional. The questions are implicit, which is easy to be accepted by the violator and can reflect the psychological and security perception of them. Practice found that as long as the investigator has a friendly attitude and asks questions in a more euphemistic way, pedestrians are willing to cooperate with the investigation. This allows the study to grasp more accurately match 
between the behavior and psychological data, greatly improving the accuracy and reliability of the research.

Binary Logistic Model. Logistic model is the earliest discrete selection model based on utility theory. In the transportation field, it is often used to analyze the problems related to decision making and choice behavior. At signalized intersection, there are two choices for pedestrian crossing decisions: compliance with regulations and violation of regulations. It is a binary classification variable, binary logistic model are used in this paper.

We view whether or not people illegally crossing as the dependent variable, if it is illegal then $y=1$; if not, $y=0$. The formula is as follows:

$$
p(y=1)=\frac{1}{1+\exp \left[-\left(\alpha+\beta_{1} X_{1}+\beta_{2} X_{2}+\beta_{3} X_{3}+\beta_{4} X_{4}+\varepsilon\right)\right]} ; p(y=0)=1-p(y=1)
$$

In this formula, $\alpha$ is a constant, $\beta$ represents the regression coefficients of the logistic model, $X_{\mathrm{i}}$ represents different independent variables , $\varepsilon$ represents error term.

\section{Results}

Logistic Model. The output of the binary logistic model is shown in the table below

Table 2. Binary logistic model output results

\begin{tabular}{|c|c|c|c|}
\hline \multicolumn{3}{|c|}{ Independent variable } & output results \\
\hline \multirow{11}{*}{$\begin{array}{l}\text { Personal } \\
\text { attributes }\end{array}$} & \multirow{4}{*}{ Age } & $<16$ & 0 reference level \\
\hline & & $16-35$ & $0.76(0.080) *$ \\
\hline & & $35-60$ & $0.12(0.230)$ \\
\hline & & $>60$ & $-0.26(0.491)$ \\
\hline & \multirow{2}{*}{ Gender } & male & 0 reference level \\
\hline & & female & $-0.47(0.793)$ \\
\hline & \multirow{5}{*}{$\begin{array}{l}\text { The number of people } \\
\text { crossing together }\end{array}$} & 1 & 0 reference level \\
\hline & & 2 & $0.57(0.181)$ \\
\hline & & 3 & $1.07(0.062) *$ \\
\hline & & 4 & $1.28(0.046) * *$ \\
\hline & & $>4$ & $1.69(0.000) * * *$ \\
\hline \multirow{15}{*}{$\begin{array}{l}\text { Illegally } \\
\text { crossing } \\
\text { attributes }\end{array}$} & \multirow{4}{*}{ Psychology of violation } & unconscious & 0 reference level \\
\hline & & anxious & $0.79(0.076) *$ \\
\hline & & fluke mind & $2.35(0.000) * * *$ \\
\hline & & herd mentality & $3.56(0.000) * * *$ \\
\hline & \multirow{4}{*}{ Danger sense } & hardly & 0 reference level \\
\hline & & a little & $0.04(0.631)$ \\
\hline & & general & $0.29(0.073) *$ \\
\hline & & very & $0.84(0.037) * *$ \\
\hline & \multirow{4}{*}{ Walking state } & walk & 0 reference level \\
\hline & & walk after run & $0.17(0.573)$ \\
\hline & & run after walk & $-0.21(0.794)$ \\
\hline & & run & $0.42(0.892)$ \\
\hline & \multirow{2}{*}{$\begin{array}{l}\text { Stop during illegally } \\
\text { crossing }\end{array}$} & yes & 0 reference level \\
\hline & & no & $-0.58(0.773)$ \\
\hline & \multicolumn{3}{|c|}{$\begin{array}{l}\text { Constant } \mathrm{B}=1.463(0.674) ; \mathrm{N}=535 ; \mathrm{R}^{2}=0.317 \\
\text { Cox\&Snell } \mathrm{R}^{2}=0.839 ; \text { Nagelkerke } \mathrm{R}^{2}=0.986 ; \text { sig value in Hosmer and } \\
\text { Lemeshow test }=0.569\end{array}$} \\
\hline
\end{tabular}

$* * *$ sig. $<1 \%, * * \operatorname{sig} .<5 \%, *$ sig. $<10 \%$

After the model test, we found that both Cox\&Snell $\mathrm{R}^{2}$ and Nagelkerke $\mathrm{R}^{2}$ squared are close to 1 and the sig. value in Hosmer and Lemeshow test is $0.569>0.05$, so the fitting of the model is good. As 
we can see from table 2, three factors: number of people crossing together, psychology of violation and danger sense have a great influence on illegally crossing. Among them, fluke mind and herd mentality are most serious. We use expectation theory to further analyze the results and put forward countermeasures.

Analysis based on Expectation Theory. The most representative theory of expectation theory ${ }^{[16]}$ (Victor Vroom) is that the degree of motivation of a goal is influenced by two factors: the target titer and the expectancy, which is described by the formula:

$$
M=V \times E
$$

Where $M$ is the level of excitation, indicating the driving force of a certain action ; $V$ is the target titer, is a value judgment of result, main affected by the concept of people. It's usually going to be [- 1, $+1]$, in this paper, $[0,1]$ is more advantageous to understand and study. The more important the result is to the individual, the more the value will approach 1, or conversely it will be close to zero.

$E$ is a subjective estimate of the likelihood of achieving the target, usually going to be $[-1,+1]$. Only when people think that the likelihood of achieving that goal is very high, they will try to achieve it.

In this study, the driving force of the violation $\left(M_{w}\right)$ has two components: the benefit of illegal behavior ( $\mathrm{t}$ ) and the punishment (f), then:

$$
M_{w}=M_{t}-M_{f}
$$

According to expectancy Theory:

$$
M_{f}=V_{f} \times E_{f}, M_{t}=V_{t} \times E_{t}
$$

Finally, we can figure out that:

$$
M_{w}=V_{t} \times E_{t}-V_{f} \times E_{f}
$$

Analysis of (5) shows that when the benefit of illegal behavior is greater than the punishment level, there will be illegal behavior, or conversely will contribute to law-abiding behavior.

\begin{tabular}{|c|c|c|}
\hline The object & Measure & Embodies the measure \\
\hline $\begin{array}{c}\text { benefit of illegal } \\
\text { behavior }\end{array}$ & decrease driving force & $\begin{array}{l}\text { Danger perception education, accident damage } \\
\text { education, traffic law publicity }\end{array}$ \\
\hline punishment & increase driving force & $\begin{array}{l}\text { Equipped with traffic police and voluntary, } \\
\text { exposure and fine }\end{array}$ \\
\hline
\end{tabular}
Accordingly, we can put forward corresponding countermeasures against pedestrian violation behavior based on herd mentality. The detailed analysis is shown in table 3:

Table 3. The analysis of driving force and measures about illegally crossing

We can start from two aspects to reduce the behavior of crossing the street illegally based on herd mentality.

1) Reduce the benefits of illegal behavior. Pay attention to risk awareness education; carry out lectures on traffic knowledge in schools; use modern media to increase traffic accident education and traffic law propaganda.

2) Increase external punishment. Equipped with traffic police at the intersection and recruited volunteers to assist the management. At the same time, the violations shall be exposed and fined. Use a variety of punishment education means, such as increasing the amount of fine, recording the violation record for personal credit system reference, etc. Of course, all kinds of punishment measures should combine the actual situation of the local. 


\section{Conclusions}

This paper studied the behavior of pedestrian illegally crossing under the influence of herd mentality. The method of timely psychological inquiry was adopted to collect data that can directly reflect the illegal psychology. Binomial logistic model was established to make quantitative analysis of the influence degree of different variables. Among them, herd mentality and fluke mind are of the most influence. Finally using expectancy theory to analysis modeling results, it is concluded that reducing benefit of illegal behavior and increasing punishment are effective countermeasures.

The research idea of this paper applies to other general signalized intersections. The logistic modeling results can provide the basis for quantitative analysis of the incentive level in the expectation theory. Combine these two methods can help decision makers make more targeted and effective countermeasures

\section{Acknowledgements}

This work was financially supported by the National Natural Science Foundation of China (Granted No.61374195).

\section{References}

[1] Information on http://data.stats.gov.cn/easyquery.htm?cn=C01\&zb=A0S0D03\&sj=2015

[2] Chu X, Guttenplan M, Baltes M: Why People Cross Where They Do: The Role of Street Environment. Transportation Research Record Journal of the Transportation Research Board. Vol.1 (2002), p.3-10.

[3] Holland C, Hill R: Gender differences in factors predicting unsafe crossing decisions in adult pedestrians across the lifespan. Accident analysis and prevention. Vol.4(2010), p.1097-1106.

[4] Holland C, Hill R: The effect of age, gender and driver status on pedestrians' intentions to cross the road in risky situations. Accident Analysis and Prevention. Vol.2(2007),p.224-237.

[5] Zaki M H, Sayed T: Automated Analysis of Pedestrian Group Behavior in Urban Settings. IEEE Transactions on Intelligent Transportation Systems. Vol.99( 2017), p.1-10.

[6] Onelcin P, Alver Y: Illegal crossing behavior of pedestrians at signalized intersections: Factors affecting the gap acceptance. Transportation Research Part F. Vol.31(2015), p.124-132.

[7] Brémond R, Tom A, Désiré L: Visual cues in pedestrian's crossing decision: in search of a quantitative model. (Transportation Research Board, United States, 2012).

[8] Marie Granié, Brenac T, et al. Influence of built environment on pedestrian's crossing decision. Accident analysis and prevention.Vol.67(2014),p.75

[9] Barton B K, Kologi S M, Siron A: Distracted pedestrians in crosswalks: An application of the Theory of Planned Behavior. Transportation Research Part F, Vol.S4-5(2016), p.129-137.

[10] Zhou Zhuping, Wang Wei, Ren Gang, et al: Model of pedestrian violation of street crossing behavior based on network theory. Journal of Beijing University of Technology. Vol.3 (2014). p. 374-377.

[11] Li Feng, Shen Huizhang, Liu Shangliang, et al: Dynamic analysis of herd behavior under crisis events based on psychological threshold model. Journal of systems management. Vol. 5(2011), P.513-519

[12] Zhou R, Horrey W J: Predicting adolescent pedestrians' behavioral intentions to follow the masses in risky crossing situations. Transportation Research Part F.Vol.3(2010),p. 153-163.

[13]Li Mei, Wang Yanni, Sun Tianyi, et al: Analysis of pedestrian violation conformity behavior based on threshold model. Shandong traffic science and technology.Vol.3( 2012),p. 48-51

[14] Li Zhenpeng, Tang Xijin: Threshold model of collective action. Systems science and mathematics. Vol.5( 2014),p.550-564

[15] Wu Wenjing. Simulation analysis of evolutionary game of pedestrians' group behaviors under influence of herd behavior. Journal of Jilin University. Vol. 47(2017), p. 92-96 
[16] Jones B T: A review of expectancy theory and alcohol consumption. Addiction. Vol. 96(2015), p. 57-72. 